\title{
The food chain of YouTubers: engaging audiences with formats and genres
}

\author{
Marju Himma-Kadakas*, Allan Rajavee*, Maarja-Liis Orgmets*, Linda Eensaar*, Ragne Kõuts-Klemm* \\ * Department of Social Studies, University of Tartu, Estonia
}

Abstract

\begin{abstract}
Traditional news media are not engaging young audiences and there has been a decline in the number of consumers of traditional media. The main news sources for teenagers in Europe and North-America are social media and friends.

Our research project outlines YouTubers' content production strategies in order to apply them in conventional news content production to attract young audiences. In this study we profiled the top YouTubers in the world, in Europe and in Estonia based on their profiles, networks, topics, genres and formats. We developed a model of analysis based on the uses and gratifications approach by Katz et al. (1974), and McQuail (2000). This framework was used in the standardised content analysis of YouTube videos.

The results present the "food chain" of different levels of YouTubers; the "food chain" refers to the copying of innovative ideas from less experienced peers, while promoting their content. The food chain also shows how most popular YouTubers generate new production practices and discursive genres. There are noticeable variations in the diversity of genres and formats between different levels of YouTubers. Diversity of content is important for sustaining and increasing audiences. YouTubers utilise specific combinations of genres and formats for certain topics across levels of the food chain. This makes it possible to develop a typology of techniques that YouTubers use to engage audiences.
\end{abstract}

Keywords: YouTube, video content, genres, topics, young audiences, uses and gratifications.

\section{Introduction}

Over the past five years the news ecosystem has changed dramatically (Bell, 2016). The consumption of traditional journalistic content, especially among teenagers, is declining, which has led to changes in audiences (Zhu \& Procter, 2015; Thurman \& Fletcher, 2017; Das \& Ytre-Arne, 2017). At the same time, due to the availability of the Internet and mobile platforms, young audiences are consuming content created by YouTubers (Khan, 2017). The usage of social media among young audiences is on the rise; in some cases more than 90 percent of teenagers are active social media users (May, 2010; Vihalemm \& Kõuts-Klemm, 2017; Bärtl, 2018; Newman et al., 2018). For teenagers, YouTube has become a substitute for television (Cunningham \& Craig, 2017). The increasing usage of social media is changing the way journalistic news content is produced, distributed and discussed (Nielsen \& Schrøder, 2014). This is why YouTube has gained the interest of politicians, educators, artists and journalistic media organisations (Khan, 2017). There have been attempts to embed news media content or topics in the YouTube environment, using the platform and/or local teenage YouTubers for this (May, 2010; Suur videopäevik..., 2017).

Cunningham's and Craig's (2017) study revealed that the young prefer YouTube to television because of the interactive, audience-oriented content, which creates communities and is authentic. YouTubers have created many specific genres and formats to engage their audiences. The videos consist of elements of conventional television genres, and they broaden the scope of genres via the mixture and playful use of different genre elements and formats. Our study endeavours to shed light upon the possibilities of adopting techniques that 
YouTubers use, and putting them into journalistic practice to engage young audiences, but this demands a systematic outlining of YouTubers' video topics, genres and formats.

The aim of the study is to outline the YouTuber's strategies of content creation that attract followers on global, European and local (Estonian) levels. The study illuminates the "food chain" of YouTubers via the analysis of their profiles, produced content and creative interdependencies. We also show the combinations in which genres and formats appear on YouTube, since this has an impact on the attention audiences pay to YouTubers. We received inspiration from the uses and gratifications approach (UGA) of Katz, Blumler and Gurevitch (1974) and McQuail (2000), and it is complemented by the worthwhileness theory (Nielsen \& Schrøder, 2014; Schrøder, 2015).

\section{Literature overview}

In this article, a YouTuber is defined as someone 1) who regularly posts videos on YouTube, 2) who has become famous due to YouTube and 3) who has a regular group of followers. In the first criterion, regular posting distinguishes the YouTuber from users who have published any content on YouTube. The second criterion means that public figures who have become famous in other areas (singers, models, TV hosts, etc.) and are also popular on YouTube are not regarded as YouTubers. The third criterion refers to the presence of an audience, and is inseparable from regular content production and publishing.

YouTube content formats differ from established film and television formats, as YouTubers strive for authentic content that helps to establish a stable community of subscribers (Cunningham \& Craig, 2017). By creating their personal channels and developing production techniques, YouTubers not only act as amateur producers but also as digital literacy educators, whose content can motivate and teach followers how to create their own videos (Choi \& Behm-Morawitz, 2017). Therefore the spread of technological knowledge has created a wide variety of different YouTube communities, which are intertwined with other groups. Members of these user groups are likely to produce the same type of content (Liikkanen \& Salovaara, 2015), but at the same time they try to differ from their peers through self-presentation to gain popularity (Hou, 2018). This learning process develops an array of technical formats and discursive genres which, we hypothesise, correlate with specific topics. In a sense, technical formats are gateways for understanding how content production methods in specific branches of genres are used to create genres' distinctive audiovisual and discursive narratives.

Therefore, it is possible to group, compare and analyse YouTubers' content development based on topics they cover, technical formats they use and discursive genres they choose. Much of the previous research into YouTube genres has been focused on specific topics and formats: lifestyle (Choi \& Behm-Morawitz, 2017), gaming (Sjöblum et al., 2017), vlogging (Bakioglu, 2016), political content (May, 2010) etc., but there are no structured typologies of user-generated content and no empirically verified models of how developments in production techniques and discursive practices spread via social media. Shao (2009) composed a theoretical model which describes the interdependence between three types of social media use: consuming (passive viewers and "lurkers"), participating (audience members interacting with content), and producing (content creators). Using UGA, Shao (2009) tried to clarify the motivations of consuming, interacting and producing user-generated media (UGM). He also argued that social media users start as 
lurkers who over time start to interact more with the content they consume. Through interaction, users break barriers of knowledge, develop social connections, become members of virtual community and, "finally, people come to produce the content on UGM" (Shao, 2009:15).

We used Shao's theoretical model to define what UGA categories were represented in YouTubers' content and therefore tried to find out how YouTubers in our sample used genres and formats to produce particular gratifications among audience members.

But besides YouTubers' production and interaction enhancement practices, we also tried to clarify the creative relationships between different YouTubers through patterns of genre and format use. We propose that, as a social media platform, YouTube has created a network which connects YouTubers through the consumption of content of established YouTubers or by directly collaborating with YouTubers. In a sense it is a lucid food chain of content concepts, in which YouTubers with smaller subscriber bases "feed off of ideas" (production practices and new approaches to discursive genres) which come from YouTube content creators who might have millions of subscribers and a larger audience reach. Research on YouTube's content commercialisation has shown that "food chain dynamics" can also be beneficial for established YouTubers, because while subscriber numbers may rise, their content becomes routinised and, due to a lack of innovative and authentic content, their cult-like fame will eventually start to diminish (Cocker \& Cronin, 2017). Beginner YouTubers' content can also be a viable source of inspiration for the established YouTuber who is seeking fresh ideas to retain audience interest and attention. In these types of processes, different discursive genres are tweaked and mixed with format techniques to create new genres and mixes of different audio-visual formats (Khan, 2017). This has also created a hierarchy ranging from more experienced to beginner YouTubers (Morreale, 2014).

For our research we used the definitional framework composed by Muuli and Perm (2017), who mapped the most common YouTube genres and definitions. Their framework is focused on defining different audio-visual text types, which they define as genres (Muuli, 2017). To describe the genres, Muuli and Perm used a twolevel approach: first describing the main genre and then different sub-genres of the main genre (Muuli, 2017). We argue that each of these main genres and its sub-categories are connected through one or more visual production formats, such as sit-down, live, screen-sharing/collab, sketch, music video and vlog (see Table 1). We have mapped out these visual techniques based on videos in our research sample.

Table 1: Main YouTube video formats used by YouTubers (Muuli \& Perm, 2017)

\begin{tabular}{|l|l|}
\hline Format & Performance \\
\hline Sit-down & $\begin{array}{l}\text { This format is usually filmed in a private room (for example in a bedroom), where } \\
\text { a YouTuber is either framed in close-up or in middle view. Collabs and challenge } \\
\text { videos are often made in sit-down format }\end{array}$ \\
\hline Live & $\begin{array}{l}\text { A YouTuber presents an event or situation as it is happening, on the air. The } \\
\text { videos are not edited. }\end{array}$ \\
\hline
\end{tabular}




\begin{tabular}{|l|l|} 
Screen-sharing/ & $\begin{array}{l}\text { The format signifies that there is more than one person in the video. For gamers, } \\
\text { screen sharing also means that the viewer can see what is going on in the game } \\
\text { and at the same time he/she can see how the gamer reacts. The gamer is usually } \\
\text { shown in a small frame in the corner of the screen. }\end{array}$ \\
\hline Sketch & $\begin{array}{l}\text { A format where a YouTuber (and/or other performers) acts and the content is } \\
\text { usually humorous. Various situations are used to illustrate something. The video } \\
\text { usually has a certain theme and pre-scripted content. There may be several short } \\
\text { clips of situations in one video and there are rapid edits. }\end{array}$ \\
\hline Music video & $\begin{array}{l}\text { Detailed, pre-scripted, elaborate videos where a YouTuber performs or presents } \\
\text { music. }\end{array}$ \\
\hline Vlog & $\begin{array}{l}\text { A YouTuber films his/her everyday life in a natural manner. Unlike live videos, } \\
\text { vlogs are edited and uploaded after editing. The narrative of the vlog is related }\end{array}$ \\
\hline
\end{tabular}

There are more than 2000 YouTubers who have at least a million subscribers, but even YouTubers with smaller audiences can make great impacts (Cunningham \& Craig, 2017: 72). This might be due to the fact that there are formats on YouTube, e.g. vlogs, DIY (Do It Yourself) and gameplay videos, that are not present in traditional news media (Cunningham \& Craig, 2017).

\section{Theoretical background of audience motivations to follow media content}

The uses and gratifications approach (UGA) explains why audiences pay attention to particular media content (Katz et al., 1974; McQuail, 2000). The utilisation of uses and gratifications relies on what the individual does with the media (Katz et al., 1974), which also means that the audience decide what content to consume.

McQuail, Blumler and Brown (1972) present a typology of the individual's interaction with media:

1) entertainment (escape from routine or problems; emotional liberation)

2) personal relations (company; social usefulness)

3) personal identity (self identification and positioning; confirmation of one's values)

4) surveillance (seeking information)

In broad terms, UGA means that the consuming of media content can gratify different needs of an individual. The gratification derives from media content and from the individual's needs and expectations. Early UGA studies on the scarcity of available media choices in the past centred on developing medium-specific 
typologies (Lee, 2013: 302). For example, television news was found to satisfy ritualised purposes, such as passing time or relaxation, and instrumental purposes, such as becoming informed (Rubin \& Perse, 1987). According to Katz et al. (1974), while television strengthened the connections with the family, participation in discussions with friends was served better by newspapers and books. Donohew et al. (1987) found that people with higher activation levels spent more time with media and public information. Funk and Buchman (1996) studied the influence of video and computer games on teenagers' self-perceptions. Conventional UGA has been revised and it has been suggested to redefine the terms "activeness" and "audience", taking into consideration the use of the Internet (Ruggiero, 2000: 20). Contemporary studies have focused on uses and gratifications connected with social media, for example motivations behind sharing, liking and disliking YouTube videos (Hanson \& Haridakis, 2008; Khan, 2017; Sjöblum et al., 2017). Choi (2015) concludes that many motivations for following media have remained the same, but it is still meaningful to re-identify and re-conceptualise the motivations that may drive people's use of news in social media (Choi, 2015: 250; Newman et al., 2018). Choi suggests classifying the motivations in social media into four categories: surveillance, socialising, getting recognition, and entertainment (Choi, 2015). The classification of motivations is useful for the YouTuber as well, but we will use a more detailed version: the concept of worthwhileness by Schrøder (2015). The author (2015) defines seven dimensions that explain why particular content is consumed by audiences: time spent, public connection, normative pressures, participatory potential, price, technological appeal and situational fit. The worthwhileness concept helps to frame knowledge of why YouTube content is consumed, especially in today's media landscape, where audiences are more in control of what they consume (Lee, 2013). The usage of digital media requires intentional activity, rather than passive reception (Sundar \& Limperos, 2013). At the same time, it is evident that particular genres appeal to one particular need that audience members may have, e.g. a news programme appealing more to the motivation to be informed, or a talk show to the motivation for opinion formation or affirmation. This is the reason why our study combined genres and topics with UGA to analyse the content of YouTube videos.

\section{Research design}

The aim of the study was to outline YouTubers' strategies of content creation that attract followers on global, European and local levels. Based on the aim of this study, we generated two research questions:

\section{RQ1: What topics, genres and formats are most frequent among YouTubers?}

This research question enables us to outline the topics, genres and formats of YouTubers, which is the first attempt to do so in academic research. The possible relations between those categories may show us whether some topics are related to certain genres or formats.

RQ2: What topics, genres and formats appeal to certain uses and gratifications?

As a sub-question we outline the possible relations between uses and gratifications and genres and topics of YouTubers. This helps to explain the possible reasons for watching content created by YouTubers and also indirectly explains why people watch YouTube. This can be used in further research; for our research group, the output is for focus group interviews. 


\section{Methodology}

Data presented in this article is based on an original survey. We selected for the analysis 75 videos from the 15 globally and regionally most subscribed YouTubers (European $\mathrm{N}=6$, Global $\mathrm{N}=4$, Local (Estonian) $\mathrm{N}=5$ ) (see Table 2).

We selected YouTubers who had the most subscribers in their regional groups. The profiling of YouTubers data was derived from the social media monitoring site SocialBlade (2018). We included YouTubers whose content was in English or in Estonian. For profiling we included the number of followers as a variable, which indicates the popularity of a YouTuber. The second variable for profiling YouTubers is the main domain of public activity, from which we excluded singing and acting to separate YouTubers from other performers, such as professional actors and singers. We did not include in the coding posting regularly, but we took it into consideration, since regularity is one component that differentiates YouTubers from people who have posted any content on YouTube. These three criteria are wide enough to embrace a variety of YouTubers and not restrict it to sit-downs or real-talks. Taking into consideration the aforementioned criteria, we distinguished globally and regionally established YouTubers based upon their subscriber numbers, which reflects the constant reach of audience. We considered YouTubers with less constant reach to be beginners who are still finding ways to grow their subscriber base regionally or globally. These beginner YouTubers have less than five years of experience with regular content publishing, less content on YouTube and, compared to established YouTubers, the beginners' audience is smaller (but growing).

Table 2: The Profile of the YouTubers in the sample (data derived by 24.09 .2017 )

\begin{tabular}{|c|c|c|c|c|c|c|c|}
\hline User name & $\begin{array}{l}\text { Joining } \\
\text { date }\end{array}$ & Age & $\begin{array}{l}\text { Regional } \\
\text { group }\end{array}$ & Gender & Country & $\begin{array}{l}\text { Number of } \\
\text { subscribers }\end{array}$ & $\begin{array}{c}\text { Number of } \\
\text { total channel } \\
\text { views }\end{array}$ \\
\hline PewDiePie & 29.02.2010 & 27 & Global/Europe & M & SWE & $\begin{array}{r}61677 \\
554\end{array}$ & $\begin{array}{r}17413113 \\
004\end{array}$ \\
\hline VanossGaming & 15.09 .2011 & 25 & Global & M & CA & $\begin{array}{r}22953 \\
071\end{array}$ & 7133975778 \\
\hline Smosh & 19.11.2005 & $29 / 30$ & Global & $M / M$ & USA & $\begin{array}{r}22668 \\
391\end{array}$ & 9079077175 \\
\hline NigaHiga & 20.06 .2006 & 27 & Global & M & USA & $\begin{array}{r}20629 \\
844\end{array}$ & 3687706728 \\
\hline KSI & 24.07.2009 & 24 & Europe & M & UK & $\begin{array}{r}18493 \\
566\end{array}$ & 4093119058 \\
\hline W2S & 26.07.2012 & 21 & Europe & M & UK & $\begin{array}{r}12114 \\
625\end{array}$ & 3280709905 \\
\hline DanTDM & 14.07.2012 & 26 & Europe & M & UK & $\begin{array}{r}18326 \\
179\end{array}$ & $\begin{array}{r}12367493 \\
237\end{array}$ \\
\hline jacksepticeye & 24.02.2007 & 27 & Europe & $M$ & IE & 18498 & 9129862201 \\
\hline
\end{tabular}




\begin{tabular}{|c|c|c|c|c|c|c|c|}
\hline & & & & & & 008 & \\
\hline VSauce & 30.07 .2007 & 31 & Europe & M & UK & $\begin{array}{r}13086 \\
311\end{array}$ & 1394356642 \\
\hline Zoella & 02.02.2007 & 27 & Europe & $\mathrm{F}$ & UK & $\begin{array}{r}12096 \\
365\end{array}$ & 1078707966 \\
\hline HD Tanel & 05.02 .2011 & 32 & Local & $M$ & EST & 47181 & 18652245 \\
\hline Sario TV & 11.03 .2012 & 19 & Local & $M$ & EST & 48270 & 3860219 \\
\hline $\begin{array}{l}\text { Rauno } \\
\text { Raiesmaa }\end{array}$ & 09.05 .2013 & 18 & Local & $M$ & EST & 29974 & 5023329 \\
\hline Victoria Villig & 22.08 .2010 & 17 & Local & $\mathrm{F}$ & EST & 31511 & 3433592 \\
\hline MarttiHallikTV & 06.09 .2015 & 27 & Local & $M$ & EST & 29056 & 5726982 \\
\hline
\end{tabular}

The top five YouTubers in European and global groups overlap regarding two YouTubers: PewDiePie and elrubiousOMG. HolaSoyGerman and Jugagerman are the same person performing on different channels. One limitation on our sample was language. Adding Spanish, Portuguese or Russian YouTubers, for example, might increase the share of some formats or genres.

The research strategy used for video analysis was standardised content analysis, which is a suitable quantitative method to analyse the appearance of different elements of qualitative content. We divided the textual elements into five large groups: profiles, topics, genres, formats, and uses and gratifications. The category of profiles was analysed on the level of the YouTuber and it consists of information about the YouTuber's username, year of joining YouTube, number of uploads, region of origin, etc. It is background information and serves to distinguish the strategies of content creation on the different levels: global, European and Estonian.

The other categories - topics, formats, genres, and uses and gratifications - were analysed on the level of particular videos. The categories of formats and topics were formed based on the visual observations of the research team. The list of codes for each category was compiled based on theoretical outlines and was tested during the pilot study.

In the category of formats (B), we coded the video content into six formats (see Muuli \& Perm, 2017), taking into account the number of actors in the video (single or multiple actors), position of the performer (sitting, moving, etc.), the recording environment (indoor/outdoor), editing of the video (longer scenes in original performances or shorter jump cuts in vlogs), sound (continuous music, speech etc.), visual narrative (originally performed sketch or commenting whilst gaming), modality of content (live or recorded), framing of speaker (screen-sharing, medium or medium close-up shot facing the camera, action cam moving with the YouTuber, etc.)

In the category of genres (C), we coded video genres into 10 different main categories (Advertisement, Challenge, How to... video, Gaming video, Performance, Humour, Compilation, Commentary and Collection video, following Muuli \& Perm, 2017) and 51 different genres, taking into account expression of the task in 
hand (taking on a challenge, instructing, reporting on the go etc.), rhetoric (satire, irony, rant, contemplating etc.), commercial material (product placement, advertising, reviewing etc.), editing of text (scripted or spontaneous), performance (dancing, singing, playing or performing sketches), presentation of content (list, vlog, sketch etc.), speech context (gaming, beauty, everyday life etc.), emotion (happy, laid back, critical, angry etc.) and audience engagement level (responding to audience feedback, clarifying situation, call up for engagement etc.). The specifications of these subcategories/subgenres helped to define the main genre. For example, if a YouTuber made a video with a funny sketch, a prank, "roasted" somebody/something, or did a parody of something/somebody, it was categorised as a humour topic video.

The fourth category (E) mapped the four main categories of the uses and gratifications approach: entertainment (escape from routine or problems, or emotional liberation), personal relations (company, or social usefulness), personal identity (self-identification and positioning, or conformation to one's values), and surveillance (seeking information etc.) (Katz et al., 1974). These were also defined by 13 subcategories, which allowed for the coding of tensions and conflicts, escapism, eliciting other strong emotions (category of entertainment), practical knowledge, connecting to social topics, community, communal values (category of social benefits), self-determination, solving dilemmas, exploring/investigating reality (category of individual identity), creating a routine/regularity, negative references (to other YouTubers), positive references (to other YouTubers) (category of creating a permanent relationship with viewers). For example, if a YouTuber insulted another YouTuber in his video, then inter alia the coding decisions were "tension and conflicts" and "negative referencing".

Many of the videos belonged to several different genres and formats, or consisted of different uses and gratifications categories, because to some extent they all complemented each other and one did not rule out another. The reliability of coding was calculated after coding all selected videos and before analysing and it was $87.7 \%$. There were three researchers who coded videos and then revised other codings. For the analysis of the videos we used lists of the most frequent topics, formats and genres. Based on the analysis, different content strategies emerged.

\section{Results}

The YouTubers included in our English- and Estonian-speaking sample created different topics, from lifestyle and gaming to travel and science. All YouTubers in our sample used humour (C6) genre narrative techniques to create a "standardised YouTuber/vlog aesthetic, incorporating now familiar rapid-fire speech, jumpy and stylised editing, 'insider' jokes, community shout-outs and collaborations" (Cunningham \& Craig, 2017: 78). An overview of profiles of the YouTubers is presented in Table 2 and in the Table in the Appendix.

\section{Global}

In the global sample group of YouTubers, the main topics were gaming and humour. These male YouTubers had created content for more than six years and they all had more than 20 million subscribers. The gaming YouTubers VanossGaming and PewDiePie both used a screen-sharing (B5.3) format but PewDiePie had also created music videos (B5.5) and, as a YouTube star with over 50 million subscribers, 
YouTube had produced a special web show starring PewDiePie. We categorised this format as other (B5.6). Both gaming YouTubers used the highlights (C4.1) genre, which allowed YouTubers to emphasise certain parts of a long-playing session (Sjöblum et al., 2017). While VanossGaming also recorded walk-through (C4.2), PewDiePie preferred to make live sessions (C4.5). To enrich the narrative, both gamers used parody (C6.5).

The YouTubers Smosh and NigaHiga both used topic humour for performative technical formats, such as sketch (B5.4) and music video (B5.5), which both YouTubers used to create content in the humour sketch (C6.1) and original music (C5.2) genres. NigaHiga also created how-to tutorials (C3.1).

The top four global English speaking YouTubers joined YouTube during different periods. While NigaHiga and VanossGaming created their channels in the mid-2000s, Smosh and PewDiePie started posting at the beginning of the 2010s. This may explain why NigaHiga and VanossGaming have used fewer genres and PewDiePie and Smosh have developed genres that were created by the YouTube pioneers NigaHiga and VanossGaming. Eventually, this repurposing of latter YouTube content brought more subscribers to PewDiePie and Smosh, and both YouTubers have passed their veteran competitors in subscription rankings. This may be evidence of lucid food chain dynamics, where previous genre content gets revamped, as authentic material gains more views and raises the number of subscribers.

\section{Europe}

The YouTubers in the European sample group have more than 10 million subscribers and cover a quite diverse range of topics. While JackSepticEye and DanTDM cover only gaming topics, KSI and W2S mix gaming with lifestyle topics. Their use of format is quite similar, but much like the previous sample group, we can divide these YouTubers into two groups by how they use genres. While JackSepticEye and DanTDM are oriented to producing gaming genre reviews (C4.3) and special gaming narrative formats (C4.6), the lifestyle-oriented KSI and W2S also create viral challenge (C2.1) genre content. This means that KSI and W2S create content in action-based challenge genres, and JackSepticEye and DanTDM use active commentary genres, such as reaction (C9.5), storytime (C9.3) and rant (C9.2).

Zoella is the only female YouTuber in our European sample and her content differs greatly from the previously mentioned British and Irish YouTubers. While she covers lifestyle topics, she also includes lifehacks (A6.2) and beauty (A6.3). To give tutorials she does not necessarily use the how-to genre (C3) narrative but also creates challenge genre (C2) content using the screen-sharing/collab format (B5.3).

Another Europe-based YouTuber who stands out in our sample is VSauce, who has dedicated his YouTube content to educational science (A6.9), life hacks (A6.2) and health (A6.5) topics, which are produced in sitdown (B5.1) and vlog (B5.6) formats. Because this popular science based how-to lifehack's (C3.6) content requires good narrative, VSauce uses reaction (C9.5), daily/weekly vlog (C9.6) and news (C9.7) commentary genre narratives. 
Local (Estonian)

The Estonian-speaking local sample group consists mostly of lifestyle YouTubers. Only the most subscribed user, HDTanel, is a pure gaming YouTuber. SarioTV and Victoria Villig have primarily created their content in original performance genre, which correlates with the topic of humour. MarttiHallikTV's, Rauno Raiesmaa's and Villig's content belong to the lifestyle topic category. Local Estonian-speaking YouTubers have over 27 000 subscribers.

The Estonian YouTube community is limited and intimate. For example, Martti Hallik (MarttiHallikTV) and Victoria Villig belong to the same creative agency, Creatly (2018), which has consolidated Estonian-speaking lifestyle topic YouTubers. One of Victoria Villig's most watched videos features Rauno Raiesmaa, who does not belong to the Creatly group. HDTanel and SarioTV do not belong to this network and do not collaborate with other YouTubers very much.

While the European level YouTubers Zoella, VSauce, KSI and W2S try to cover many topics, the Estonianspeaking YouTubers usually stick to one certain topic: lifestyle (MarttiHallikTV, Victoria Villig and Rauno Raiesmaa), gaming (HDTanel) or humour (SarioTV). Also, Estonian YouTubers rely heavily on sit-down (B5.1) and screen-sharing/collab (B5.3) formats. SarioTV, Rauno Raiesmaa and Victoria Villig have also used the sketch (B5.4) and music video (B5.5) formats to create performance (C5) and humour (C6) genre category content. It is quite obvious why Estonian YouTubers use reaction (C9.5) and rant genres (C9.6) discursive narrative in their content.

While uploading statistics, an interesting production pattern emerged. YouTubers who used the gaming format had uploaded over a thousand videos on YouTube. For example, PewDiePie (Global) had uploaded 3454 videos, Jacksepticeye (Europe) 3670 videos and HDTanel (Local - Estonian) had uploaded 1171 videos. For comparison, the most popular humour channel, Smosh (Global), had 957 uploads, the educational YouTuber VSauce (Europe) had uploaded 370 videos and the most subscribed local (Estonian) satire channel, SarioTV, had uploaded only 49 videos. This difference can be explained by the very different nature of producing lifestyle and humour compared to gaming videos. While gamers usually use spontaneous commentary, which is based on the video games narrative, humour and lifestyle YouTubers have to create their genre discursive narrative from scratch. Also, recording screen-sharing gaming videos is a much easier production process than setting up a studio for the sit-down format or working with mobile recording devices. It is important to note that the quite remarkable difference in the number of subscribers between local (Estonian) and Europe/global sample groups can be explained by the number of potential viewers and subscribers within the language space, but language space impact on YouTube content dissemination will not be discussed in this article; as an important variable, this question needs further research.

\section{Topics: humour and lifestyle}

Based on the most viewed videos of YouTubers, the most popular topics were humour, lifestyle and games. The topics that appeared in the sample videos were: humour (60\%), lifestyle (53\%), gaming (47\%), lifehacks (14\%), and travel, science, health and beauty (each of them $7 \%$ ). 
While humour and games are relatively narrow and clear in their topical profiles, lifestyle is more versatile and may contain a range of videos, from applying make-up to more consumer-related content. This may also explain the high frequency of this topic. Closely related to lifestyle is the topic of beauty. Although our sample contained only one YouTuber (Zoella) who posts videos on beauty, there are a number of YouTubers who cover this topic. Since beauty is inherently very similar no matter who is posting on this topic, this might explain why there is only one beauty YouTuber in our sample: viewers are divided between different channels, which prevents other YouTubers on this topic from gaining prominence.

The topic of beauty is closely related to the topic of lifehacks, which was more represented in our sample than beauty. There were fewer videos in our sample on the topics of health and science. This may be explained by the fact that these topics do not appeal as much to young people, who are the main audience for YouTubers.

The most popular topics related to the worthwhileness (Schrøder, 2015) dimensions of normative pressure and participatory potential. Games, humour and lifehacks can encourage people to participate (to create/cocreate or act on suggested advice) and use normative pressures (offer common topics with peers). Games relate to the public connection, by relating to peers and time spent. Creating similar content is technologically very easy, even with smart phones, and encourages people to create and participate. Popular topics also relate to the typology of the individual's interaction with media (McQuail et al., 1972) in the categories of entertainment, personal relations and personal identity, but not as much with surveillance. The latter refers to information seeking, which may also explain the low representation of the science and health topics, which are more oriented towards giving information, and less to participation and participatory potential.

\section{Genres: gaming and original performance}

We grouped the genres according to global, European and local (Estonian) YouTubers in order to determine the differences between them (Table 3). The global and European sample groups share more similarities with each other than with the local group of YouTubers. Two genres - gaming and original performance are strongly related to global and European YouTubers, but less related to locals. Locally relevant genres are advertisement and challenge, which might be related to the aforementioned Estonian creative grouping of YouTubers called Creatly. The entrepreneurial formation of YouTubers has led to more commercialised content, which may explain the dominance of advertising content.

Table 3: The main genres of YouTube videos in the sample and their frequencies in the regional groups.

\begin{tabular}{|l|c|c|c|c|}
\hline Genre & $\begin{array}{c}\text { Total number of } \\
\text { videos in a } \\
\text { particular genre } \\
(\mathrm{N}=75)\end{array}$ & $\begin{array}{c}\text { Videos in the } \\
\text { global group } \\
(\%)\end{array}$ & $\begin{array}{c}\text { Videos in the } \\
\text { European group } \\
(\%)\end{array}$ & $\begin{array}{c}\text { Videos in the local/ } \\
\text { Estonian group (\%) }\end{array}$ \\
\hline $\begin{array}{l}\text { Original performance } \\
\text { (C5.3) }\end{array}$ & 28 & 15 & 13 & 7 \\
\hline Gaming video (C4) & 26 & 13 & 15 & 8 \\
\hline Humorous sketch (C6.1) & 20 & 9 & 9 & 7 \\
\hline
\end{tabular}




\begin{tabular}{|c|c|c|c|c|}
\hline Highlights (C7.3) & 18 & 11 & 7 & 7 \\
\hline Advertisement (C1) & 17 & 3 & 8 & 12 \\
\hline Challenge (C2) & 17 & 0 & 12 & 11 \\
\hline Original music (C5.2) & 13 & 7 & 7 & 4 \\
\hline Parody (C6.5) & 10 & 4 & 5 & 4 \\
\hline How to ... (C3) & 9 & 4 & 7 & 1 \\
\hline Reaction (C9.5) & 9 & 0 & 4 & 8 \\
\hline Other (C6.6) & 9 & 7 & 4 & 1 \\
\hline Rant (C9.4) & 8 & 0 & 3 & 8 \\
\hline Roasting (C6.4) & 8 & 0 & 3 & 8 \\
\hline Bloopers (C6.3) & 8 & 3 & 5 & 3 \\
\hline TOP (C7.1) & 7 & 0 & 1 & 8 \\
\hline Prank (C6.2) & 6 & 0 & 1 & 7 \\
\hline List (C7.2) & 6 & 0 & 0 & 8 \\
\hline Vlog (C9.6) & 6 & 0 & 7 & 1 \\
\hline News (C9.7) & 5 & 0 & 7 & 0 \\
\hline Storytime (C9.3) & 4 & 0 & 5 & 0 \\
\hline Chit-chat (C9.1) & 2 & 0 & 1 & 1 \\
\hline Collection videos (9.10) & 1 & 0 & 1 & 0 \\
\hline Cover (C5.1) & 1 & 0 & 1 & 0 \\
\hline
\end{tabular}

Combining all of the YouTubers in our sample, we see that the most frequent genres are gaming and original performance (Table 3). Gaming videos are technologically easy to create, since they require merely a webcam and a computer. Therefore gaming makes use of the technological appeal according to the worthwhileness theory. Original performance and sketch require acting skills, but at the same time they make it possible to create entertaining videos and form personal relations through those videos. Original performance correlates to the UGA categories (Katz et al., 1974) of tensions and conflicts, emotional gratification, and social interaction.

Advertisement is not a genre YouTubers are explicitly exposed to. Advertisement is frequently indistinguishable from other content; product placement or other forms of advertising are used subtly. Another genre whose purpose is somewhat more than just creative expression, is challenge, which engages different YouTubers in order to collaboratively increase audience.

News, storytime, chit-chat and collection videos were modestly represented in our sample. This may be due to the domination of gamers and humour sketches in the sample. 
Formats: screen-sharing, collab and sketch

Analysing the videos of YouTubers by region, we see that all local, European and global YouTubers produce mostly screen sharing and collab, because these formats are technologically the most accessible and the collaborative production of content is discursively most diverse in its outcome.

The most frequent formats in our sample were screen-sharing/collab, sketch, sit-down and music video (Table 4). The frequency of screen-sharing/collab is related to the fact that almost half of the 15 YouTubers have created gaming videos, which use the screen-sharing format, so the viewer can see the game and simultaneously the reactions of the player. Some gamers (e.g. VanossGaming) allow multiple players and they never show their faces. But the players communicate with each other during the game and this makes the format also a collab.

Table 4: Video formats in the sample and their frequencies in the regional groups

\begin{tabular}{|l|c|c|c|c|c|}
\hline & \multicolumn{2}{|c|}{$\begin{array}{c}\text { Total number of videos } \\
\text { in a particular format }\end{array}$} & \multicolumn{3}{c|}{ Videos in regional groups (\%) } \\
\cline { 2 - 6 } & $\mathrm{N}=75$ & $\%$ & Global & European & Local/ Estonian \\
\hline $\begin{array}{l}\text { Screen-sharing/collab } \\
\text { (B5.3) }\end{array}$ & 27 & 36 & 40 & 30 & 44 \\
\hline Sketch (B5.4) & 17 & 23 & 35 & 17 & 20 \\
\hline Sit-down (B5.1) & 13 & 17 & 0 & 20 & 28 \\
\hline Music video (B5.5) & 13 & 17 & 20 & 20 & 12 \\
\hline Vlog (B5.6) & 8 & 11 & 0 & 27 & 0 \\
\hline Other (B5.7) & 6 & 8 & 5 & 3 & 16 \\
\hline Live (B5.2) & 0 & 0 & 0 & 0 & 0 \\
\hline
\end{tabular}

Sketch as a format is related to the genres of humour and lifestyle, which are popular among YouTubers. Sit-down is more related to the topic of beauty, which can be related to many different genres. In our sample there was a modest representation of vlogs. This may be because vlogs inherently demand linear and occasionally real-time watching, which is not as popular or suitable on YouTube. At the same time, music video, which does not require viewing in real-time, is not as time dependent. The high proportion of music videos can also be explained by the fact that such TV music channels as MTV are not accessible and therefore not as popular among teenagers, and YouTube has taken their place. YouTubers, by publishing music videos, may be trying to gain the attention of the audience, as well as music producers.

Previous research (Khan, 2017) has shown that YouTube audiences are likely to participate in content creation and even remix the content from subscribed channels. In addition, the Kahn survey results show that YouTube audiences who actively engage with subscribed content using their real names are more likely to upload their own content to the platform for self-identifying purposes (Khan, 2017). Uploading vlogs and other lifestyle videos has also been linked to the "desire to inform the audience, and connecting with others 
regarding the common experience" (Snelson, 2013: 334). This participatory culture has been an essential part of building the community of YouTubers and active audience members who want to produce and consume authentic content which is "a fully fledged critique of legacy media, striking at its core of wellimagined stories, well-told, following established narrative-fiction conventions, produced, written and acted by appropriately trained professionals" (Cunningham \& Craig, 2017: 74).

\section{Lucid food chain of YouTubers}

When we take into account that beginner YouTubers actively watch which content is uploaded by established content creators, experienced YouTubers try to determine who are the new creators in their preferred established YouTube genres (Morreale, 2014: 119). These communities have the dynamic of a lucid food chain of genres and format ideas, where beginners feed off established content creators' ideas and vice versa. For example, if a beginner YouTuber wants to upload a gaming video, he or she usually imitates the production practices of more established gaming genre YouTubers (PewdiePie, Vanossgaming, JackSepticEye etc.). This "lucidity" in the "food chain" means that established YouTubers may also pick up new content ideas from beginners (Morreale, 2014; Cocker \& Cronin, 2017).

Our research has found that the most evenly spread genres are the original music, gaming, original performance, humour sketch, parody and highlights genres, which are all represented in different groups of our sample (Table 3). The most widespread technical formats are screen-sharing, sketch and music video (Table 4). The most evenly represented topic groups are gaming and humour (Table 6), but this does not show objectively the total dissemination of the genre amongst all YouTubers, which would show the full impact of the lucid food chain effect on specific YouTube topic branches. There are limitations to our analysis of food chain dynamics because we are comparing the most popular YouTubers, who use different genres and formats.

The topics on YouTube are diverse. For example, the British YouTubers KSI and W2S use a combination of the three most represented topics (humour, games and lifestyle) in our sample for their content creation. By widening their topic scope, they can attract more attention from different virtual communities (Shao, 2009). Our findings also show that YouTubers in the local (Estonian) group aren't keen to mix topics, but tend to choose one focus topic (lifestyle, humour or gaming). The same conservative use of topics can be detected amongst global sample group YouTubers whose large subscription base does not provide greater creative freedom, but the process of commercialisation and content routinisation may lead to a diminishing of YouTubers' subscriber base (Cocker \& Cronin, 2017).

Therefore it is more accurate to consider what categories of uses and gratifications are shared amongst content created by YouTubers in our sample (Table 5). The most commonly shared category of UGA is eliciting emotions, which has an over $15 \%$ frequency in all regional groups. This means that the most popular content is often created on emotional narrative. That is why the second most represented UGA category is releasing tensions and conflict, which is strongly tied to eliciting emotions. Widespread UGA categories include dilemma solving and reality clearing. 
Table 5: The uses and gratifications category in the content of videos in the regional groups

\begin{tabular}{|c|c|c|c|c|}
\hline & $\begin{array}{l}\text { Total } \\
\text { number of } \\
\text { videos } \\
\text { referring to } \\
\text { a UGA } \\
\text { category } \\
(\mathrm{N}=75)\end{array}$ & Global (\%) & European (\%) & $\begin{array}{l}\text { Local/ Estonian } \\
\text { (\%) }\end{array}$ \\
\hline Eliciting emotions (E1.3) & 49 & 25 & 17 & 23 \\
\hline Tension and conflicts (E1.1) & 41 & 21 & 11 & 23 \\
\hline Community (E2.3) & 38 & 23 & 15 & 13 \\
\hline Escapism (E1.2) & 25 & 13 & 13 & 7 \\
\hline Dilemma solving (E3.2) & 25 & 9 & 19 & 5 \\
\hline Uniting social talk (E2.2) & 22 & 3 & 9 & 17 \\
\hline Self-definition (E3.1) & 20 & 1 & 11 & 15 \\
\hline Investigating reality (E3.3) & 18 & 4 & 8 & 12 \\
\hline $\begin{array}{l}\text { Negative reference to other } \\
\text { YouTubers (E4.2) }\end{array}$ & 18 & 1 & 7 & 5 \\
\hline Creating routine (E4.1) & 17 & 0 & 7 & 16 \\
\hline Common values (E2.4) & 14 & 1 & 12 & 5 \\
\hline Practical knowledge (E2.1) & 14 & 3 & 8 & 8 \\
\hline $\begin{array}{l}\text { Positive reference to other } \\
\text { YouTubers (E4.3) }\end{array}$ & 12 & 0 & 11 & 16 \\
\hline
\end{tabular}

These results show that both well-established YouTubers and beginners mostly strive to include the same UGA categories to get more attention from audiences. To fulfil the expectations of audiences, beginners intuitively choose formats and genres which are used by the global trendsetters and try to make their own discursive and/or visual narrative based on trendsetters' content. If beginners' content matches all of the UGA categories and gains popularity on a social network, then it may be picked up by established YouTubers. We believe that these findings provide evidence of a lucid food chain dynamic in the YouTubers' global community.

\section{The hierarchical structure of YouTubers}

The profiling of YouTubers and their video topics, technical formats and discursive genres makes it possible to outline the patterns that categorise YouTubers' content. But YouTubers' positioning in the YouTuber hierarchy is in correlation with the number of channel subscribers, because it shows the audience's longterm interest in YouTubers' content (Choi \& Behm-Morawitz, 2017). This leads to a sub-question: is there a 
relationship between the representation of uses and gratifications in the videos and the subscription-based hierarchical structure between YouTubers?

Creating a sense of digital self on YouTube begins through content consumption (Chen, 2014). If an audience member wants to make the transition from viewer to producer of YouTube content, the previously watched content defines the topic scope that the aspiring YouTuber chooses for his or her content creation starting point. According to Shao (2009), when a participating user chooses to start producing regular content this constitutes an act of self-expression and self-actualisation during which the developing content creator (apart from constructing a digital self) forms social relationships with other content creators. The main way to forge virtual relationships with other YouTubers and also grow a loyal subscriber base is by participating in commentary, because responding with feedback and discussing content is the key to forming social relationships (Jarret, 2008).

Table 6: The main topics of videos in the sample and in the regional groups

\begin{tabular}{|c|c|c|c|c|}
\hline & $\begin{array}{l}\text { Total number of } \\
\text { videos }(\mathrm{N}=75)\end{array}$ & $\begin{array}{l}\text { Videos in the } \\
\text { global group (\%) }\end{array}$ & $\begin{array}{l}\text { Videos in the } \\
\text { European group } \\
(\%)\end{array}$ & $\begin{array}{l}\text { Videos in the local/ } \\
\text { Estonian group (\%) }\end{array}$ \\
\hline Humour (A6.7) & 9 & 20 & 27 & 13 \\
\hline Lifestyle (A6.1) & 8 & 0 & 33 & 20 \\
\hline Gaming (A6.4) & 7 & 13 & 27 & 7 \\
\hline Lifehacks (A6.2) & 2 & 0 & 13 & 0 \\
\hline Travel (A6.8) & 1 & 0 & 7 & 0 \\
\hline Science (A6.9) & 1 & 0 & 7 & 0 \\
\hline Health (A6.5) & 1 & 0 & 7 & 0 \\
\hline Beauty (A6.3) & 1 & 0 & 7 & 0 \\
\hline Food (A6.6) & 0 & 0 & 0 & 0 \\
\hline
\end{tabular}

We focused on YouTubers' video content and coded in our UGA referencing categories the occurrences of positive or negative reference to other YouTubers in the sample videos. The results show that positive references to other YouTubers was most frequent in the local (Estonian) group (16\%) and in the European group videos (11\%). In the global group, we didn't register any occurrences of positive references to other YouTubers and the negative reference frequency in the global group videos was marginal. Negative references in the local (Estonian) (5\%) and the European group (7\%) videos were more frequent than in the global sample.

YouTubers with a global reach tend to routinise their content so that every member of their large audience is guaranteed to get the content they are accustomed to (Cocker \& Cronin, 2017). This trend was revealed by our content analysis, where global YouTubers' videos contained references to creating a sense of community (23\%). UGA community category occurrences were also coded in local (Estonian) (13\%) and European (15\%) videos. We believe that the global-level YouTubers are not that keen to collaborate with other YouTubers, because they have already established their subscription positions based on hierarchy and 
their main objective is to sustain audience attention and commercialised content production. European and local (Estonian) groups in the sample of YouTubers referred more to other YouTubers, which means that if the competition for subscriber attention is potentially closer then interactions with other YouTubers are more common.

\section{Conclusions}

We profiled and analysed the top subscribed YouTubers' content on three levels: globally, European and local. Our findings show that YouTubers on all of our sample levels tended to prefer topics related to humour $(60 \%)$, lifestyle (53\%) and games (47\%). Such topics as beauty, science, health and travel were represented in our sample scope, but these topics shared the same frequency in the sample and were rather marginal (7\%). This can be explained by the fact that out of 15 YouTubers in the sample 13 were male between the ages of 18 and 32. Gaming topic YouTubers are effective producers of content as their content production methods are simple and don't need editing, and the narrative of the video is often dictated by the video game the YouTuber is playing. This means that breaking Shao's (2009) user-generated media model barriers is much easier in the gaming topic.

Our findings suggest that certain YouTube content topics are linked with certain technical formats. In our video sample, the four most common formats were screen-sharing/collab (36\%), sketch (23\%), music video $(17 \%)$, and sit-down (17\%). The screen-sharing/collab format is mainly used by the gamers PewDiePie, VanossGaming, Jacksepticeye, W2S, DanTDM et al. Based on YouTubers' format use and topic choice, the same parallel can be drawn between format sit-down and topic lifestyle. Also, YouTubers who have chosen humour as a topic usually use sketch or music video format.

While formats define the technical and audio-visual aspects of YouTube content, YouTubers use such discursive genres as activity challenges, commentary rants or content repurposing by making a highlight genre in which audio-visual juxtaposition between different clips may help to clarify some situation, narrative or event (Bowyer et al., 2017). It is difficult to analyse genres in YouTube because the constant influx of new user-generated content means there is a constant process of hybridisation between different genres (Scolari \& Fraticelli, 2017). As with topics and formats, there is a similar link between formats and genres. For example, original performance is frequently (19\%) used in sketch formats, but at the same time our sample YouTubers used original performance, also producing content in sit-down (8\%), screensharing/collab (7\%) and music video (4\%). While the frequency of using the original performance genre in these formats was low, it still provides evidence that some YouTubers in our sample remixed discursive genres and technical formats to upload authentic content for self-identifying purposes (Khan, 2017).

Our findings show that the genres that link to most UGA categories are performative original performance, which has an especially strong connection with tensions and conflicts (20\%), eliciting other strong emotions (21\%) and building community (17\%). It should also be noted that original performance had connections to all of the UGA categories used in this research. When we put this relationship into the context of Shao's user-generated media model, original performance is the very definition of self-expression and for this audience members feel strong emotions, especially when the content isn't satire. Also, gaming genres are closely connected with escapism (20\%), which is offered by video games, and eliciting emotions (24\%) 
through fictional entertainment. One of the results of the study was that YouTubers' intent was not to provide informational content, which contradicts one of the aims of this research project: to copy practices from YouTubers and use them in journalistic content production. This raises the question of whether YouTuber practices are transferable to journalism and if so, to what extent? We hope to answer this question in our next study, where we take into consideration audience expectations regarding content.

We analysed the occurrence of UGA categories on global and regional levels. We found similarities but also disparities. All levels of YouTubers produce videos which fulfil the UGA category of eliciting emotions (global $25 \%$, Europe $17 \%$, local 23\%). While emotional expression is common to "standardised YouTuber/vlogger aesthetics" (Cunningham \& Craig, 2017), the tension and conflicts categories tend to occur on both the global and local levels.

Compared to the global and European sample, local YouTubers made more effort to fulfil the UGA of uniting social talk/topics (global 3\%, Europe 9\%, local 17\%). Local YouTubers also were more focussed on creating a routine (global $0 \%$, Europe $7 \%$, local $16 \%$ ) and positive references to other YouTubers (global 0\%, Europe $11 \%$, local $16 \%$ ). Local YouTubers also showed considerably higher frequency than global in the UGA category of uniting social talk (global 3\%, Europe 17\%, local 17\%).

To better understand how creative relationships, new discursive genres and technical formats are born and spread on YouTube, we propose that there is an interdependence dynamic that can be described as a "lucid food chain" of genres and format ideas, where beginners feed off established content creators' ideas and vice versa. Our lucid food chain model is focused on showing how the most successful content production techniques are passed on to beginner YouTubers. Our findings show that there are topics (lifestyle, gaming and humour), formats (screen-sharing/collab, sketch, music video and sit-down) and genres (original music, gaming, original performance, humour sketch, parody and highlights) that were used frequently in the most popular content by the YouTubers in our sample. To see if the common genres and formats also had the same appeal, we analysed how YouTubers' content fulfilled different UGA categories. The data show that the strongest community values and communal interaction was on the local (Estonian) level. Global-level, well-established YouTubers seem to be keen on building their own community but do not refer to common values or positive or negative relationships with other YouTubers. European-level YouTubers, where genre and format use is the most diverse, fulfilled the UGA categories quite evenly, as all of the categories were represented in our results. In conclusion, the proposed theoretical food chain needs additional empirical support, which could be provided by analysing different genres in greater depth and by analysing networks of YouTubers and multi-channel networks which are formed by media companies trying to reap profit from the YouTuber phenomena. But our research shows that a strong virtual community, which is formed at least on the local level, motivates users to become involved in self-actualisation.

\section{Funding}

The work was supported by the institutional research funding IUT20-38 from the Estonian Ministry of Education and Research. 


\section{References}

Bakioglu, B. (2016). Exposing convergence: YouTube, fan labour, and anxiety of cultural production in Lonelygirl15. Convergence: The International Journal of Research into New Media Technologies, 121. https://doi.org/10.1177/1354856516655527

Bell, E. (2016). Facebook is eating the world. Columbia Journalism Review [retrieved from https://www.cjr.org/analysis/facebook and media.php, on $18^{\text {th }}$ June 2017].

Bowyer B., Kahne J., \& Middaugh, E. (2017). Youth comprehension of political messages in YouTube videos. New Media \& Society, 19, 522-541.

Bärtl, M. (2018). YouTube channels, uploads and views: A statistical analysis of the past 10 years. Convergence: The International Journal of Research into New Media Technologies, 24(1), 16-32.

Chen, C. P. (2014). Forming digital self and parasocial relationships on YouTube. Journal of Consumer Culture, 16(1), 232-254.

Choi, J. (2015). Why do people use news differently on SNSs? An investigation of the role of motivations, media repertoires, and technology cluster on citizens' news-related activities. Computers in Human Behavior, 54, 249-256.

Choi, Y. G., \& Behm-Morawitz, E. (2017). Giving a new makeover to STEAM: Establishing YouTube beauty gurus as digital literacy educators through messages and effects on viewers. Computers in Human Behavior, 73, 80-91.

Cocker, H. L., \& Cronin, J. (2017). Charismatic authority and the YouTuber: Unpacking the new cults of personality. Marketing Theory, 17(4), 455-472.

Creat.ly (2018). About us, [retrieved from https://creat.ly/meist/30. on 12. March 2018].

Cunningham, S., \& Craig, D. (2017). Being 'really real' on YouTube: authenticity, community and brand culture in social media entertainment. Media International Australia, 164, 71-81.

Das, R., \& Ytre-Arne, B. (eds.) (2017). Audiences, towards 2030. Priorities for audience analysis. Surrey: CEDAR. [retrieved from http://epubs.surrey.ac.uk/842403/ on 12 March 2018].

Donohew, L., Palmgreen, P., \& Rayburn II, J. D. (1987). Social and psychological origin of media use: A lifestyle analysis. Journal of Broadcasting \& Electronic Media, 31(3), 255-278. https://doi.org/10.1080/08838158709386663

Funk, J. B., \& Buchman, D. D. (1996). Playing Violent Video and Computer Games and Adolescent SelfConcept. Journal of Communication, 46(2), 19-32. https://doi.org/10.1111/i.14602466.1996.tb01472.x

Hanson, G., \& Haridakis, P. (2008). YouTube Users Watching and Sharing the News: A Uses and Gratifications Approach. Journal of Electronic Publishing, 11(3). http://dx.doi.org/10.3998/3336451.0011.305

Hou, M. (2018). Social media celebrity and the institutionalization of YouTube". Convergence: The International Journal of Research into New Media Technologies. https://doi.org/10.1177/1354856517750368

Jarret, K. (2008). Beyond broadcast yourself: The future of YouTube. Media International Australia, 126, 132-144. 
Katz, E, Blumler, J.G., \& Gurevitch, M. (1974). Utilization of Mass Communication by Individual in Blumler, J. G. and Katz, E (eds.) The Uses of Mass Communications: Current Perspective on Gratifications Research (pp. 19-32), Beverly Hills, CA: Sage.

Khan, L. M. (2017). Social media engagement: What motivates user participation and consumption on YouTube? Computers in Human Behavior, 66, 236-247.

Lee, A. M. (2013). News Audiences Revisited: Theorizing the Link Between Audience Motivations and News Consumption. Journal of Broadcasting \& Electronic Media, 57(3), 300-317.

Liikkanen, L., \& Salovaara, A. (2015). Music on YouTube: User engagement with traditional, userappropriated and derivative videos. Computers in Human Behavior, 20(2), 224-244.

May L. A. (2010). Who Tube? How YouTube's News and Politics Space Is Going Mainstream. International Journal of Press/Politics, 15, 499-511.

McQuail, D. (2000). McQuail's Mass Communication Theory. 4th Edition. London: Sage.

McQuail, D., Blumler, J. G., \& Brown, J. (1972). The television audience: a revised perspective, in D. McQuail (ed.), Sociology of Mass Communication (pp. 135-65). Harmondsworth: Penguin.

Morreale, J. (2014). From homemade to store bought: Annoying Orange and the professionalization of YouTube. Journal of Consumer Culture, 14(1), 113-128.

Muuli, L.M. (2017). Eesti youtuberite eneseesit/us, auditooriumi ja privaatsuse taju. Unpublished Bachelor Thesis. Tartu: University of Tartu.

Muuli, L.M., \& Perm, K. (2017). YouTube'i keskkonnas kasutatavate mõistete ja žanrite definitsioonid. (juh). M. Murumaa-Mengel \& A. Siibak. Kodutöö kursusel "Contemporary Issues of Information Age". Tartu: Tartu Ülikool.

Newman, N., Fletcher, R., Kalogeropoulos, A., Levy, D. A. L., \& Nielsen, R. K. (2018). Reuters Digital News Report [retrieved from https://reutersinstitute.politics.ox.ac.uk/sites/default/files/digital-newsreport-2018.pdf on 15 June 2018].

Nielsen, R. K., \& Schrøder, K. C. (2014). The relative importance of social media for accessing, finding, and engaging with news: An eight-country cross-media comparison. Digital Journalism, 2(4), 472-489.

Rubin, A. M., \& Perse, E. (1987). Audience activity and television news gratifications. Communication Research, 14(1), 58-84.

Ruggiero, T. E. (2000). Uses and Gratifications Theory in the 21st Century. Mass Communication \& Society, $3(1), 3-37$.

Schrøder, K. C. (2015). News Media Old and New. Journalism Studies, 16(1), 60-78.

Scolari, C., \& Fraticelli D. (2017). The case of the top Spanish YouTubers: Emerging media subjects and discourse practices in the new media ecology, Convergence: The International Journal of Research into New Media Technologies, 1-20.

Shao, G. (2009). Understanding the appeal of user-generated media: a uses and gratification perspective, Internet Research, 19(1), 7-25.

Sjöblum, M., Törhönen, M., Hamar, J., \& Macey, J. (2017). Content structure is king: An empirical study on gratifications, game genres and content type on Twitch. Computers in Human Behavior, 73, 161171.

Snelson, C. (2013). Vlogging about school on YouTube: An exploratory study. New Media \& Society, 17(3), 321-339. 
Socialblade (2018). https://socialblade.com/info [retrieved from https://socialblade.com/info on the 29 . August 2017 and 24. April 2018].

Sundar, S. S., \& Limperos, A. M. (2013). Uses and Grats 2.0: New Gratifications for New Media. Journal of Broadcasting \& Electronic Media, 57, 504-525.

Suur videopäevik: Kõik vlog'id koos! Vaata, kuidas veetis Karl Vilhelm Valter aega XII noorte laulu- ja tantsupeol. Delfi, 4. July 2017. [Retrieved from http://www.delfi.ee/archive/suur-videopaevik-koikvlogid-koos-vaata-kuidas-veetis-karl-vilhelm-valter-aega-xii-noorte-laulu-jatantsupeol?id=78767812 $20^{\text {th }}$ November 2017]

Thurman, N., \& Fletcher, R. (2017). Has Digital Distribution Rejuvenated Readership? Revisiting the Age Demographics of Newspaper Consumption. Journalism Studies. https://doi.org/10.1080/1461670X.2017.1397532

Vihalemm, P., \& Kõuts-Klemm, R. (2017). Meediakasutuse muutumine: internetiajastu saabumine. P. Vihalemm, M. Lauristin, V. Kalmus, ja T. Vihalemm (Toim), Eesti ühiskond kiirenevas ajas. Uuringu "Mina. Maailm. Meedia" 2002-2014 tulemused. Tartu: Tartu Ülikooli Kirjastus, 251-273.

Zhu, Y., \& Procter, R. (2015). Use of blogs, Twitter and Facebook by UK PhD Students for Scholarly Communication, Observatorio (OBS*) Journal, 9(2), 29-46.

Appendix: Coding of the YouTubers' video content in the sample.

\begin{tabular}{|c|c|c|c|c|}
\hline User name & $\begin{array}{l}\text { Number of } \\
\text { uploads }\end{array}$ & Topic (A) & Format (B) & Genre (C) \\
\hline PewDiePie & 3,454 & $6.4 ; 6.7$ & $5.3 ; 5.5 ; 5.7$ & $4.1 ; 4.5 ; 6.1 ; 6.5 ; 7.3$ \\
\hline Vanossgaming & 957 & 6.4 & 5.3 & $4.1 ; 4.2 ; 4.3 ; 6.5 ; 7.3$ \\
\hline Smosh & 778 & 6.7 & $5.4 ; 5.5$ & $1.7 ; 5.2 ; 5.3 ; 6.1 ; 6.5$ \\
\hline NigaHiga & 332 & 6.7 & $5.4 ; 5.5$ & $1.7 ; 3.1 ; 5.2 ; 5.3 ; 6.1 ; 6.3$ \\
\hline KSI & 1,127 & $6.1 ; 6.4 ; 6.7$ & $5.5 ; 5.6$ & $1.6 ; 2.1 ; 5.2 ; 6.3 ; 6.5 ; 7.1$ \\
\hline W2S & 632 & $\begin{array}{l}6.1 ; 6.4 ; 6.7 ; \\
6.8\end{array}$ & $5.3 ; 5.5 ; 5.6$ & $\begin{array}{l}2.1 ; 2.6 ; 4.1 ; 5.2 ; 6.3 ; 6.4 ; 6.5 ; 7.3 ; \\
9.5\end{array}$ \\
\hline DanTDM & 2,763 & $6.1 ; 6.4$ & $\begin{array}{l}5.1 ; 5.3 ; \\
5.4 ; 5.6\end{array}$ & $\begin{array}{l}4.1 ; 4.3 ; 4.6 ; 5.3 ; 6.1 ; 6.4 ; 7.3 ; 9.3 ; \\
9.4 ; 9.5\end{array}$ \\
\hline jacksepticeye & 3,670 & $6.1 ; 6.4$ & $5.3 ; 5.4 ; 5.5$ & $1.4 ; 4.3 ; 4.6 ; 5.1 ; 5.3 ; 6.1 ; 6.6 ; 9.5$ \\
\hline VSauce & 370 & $\begin{array}{l}6.2 ; 6.5 ; 6.7 ; \\
6.9\end{array}$ & $5.1 ; 5.6$ & $1.6 ; 3.6 ; 5.3 ; 9.4 ; 9.6 ; 9.7$ \\
\hline Zoella & 371 & $\begin{array}{l}6.1 ; 6.2 ; 6.3 ; \\
6.7\end{array}$ & $5.3 ; 5.7$ & $2.5 ; 2.6 ; 6.3 ; 6.5 ; 9.1 ; 9.10$ \\
\hline HD Tanel & 1,171 & 6.4 & $5.3 ; 5.7$ & $1.4 ; 1.5 ; 3.1 ; 4.1 ; 4.2 ; 6.5 ; 7.3 ; 9.5$ \\
\hline
\end{tabular}




\begin{tabular}{|l|r|l|l|l|}
\hline Sario TV & 49 & 6.7 & $5.1 ; 5.3 ; 5.5$ & $5.2 ; 5.3 ; 6.1 ; 6.4 ; 7.1 ; 7.2 ; 9.4 ; 9.5$ \\
\hline $\begin{array}{l}\text { Rauno } \\
\text { Raisemaa }\end{array}$ & 114 & 6.1 & $\begin{array}{l}5.1 ; 5.3 ; \\
5.4 ; 5.5\end{array}$ & $\begin{array}{l}2.1 ; 2.1 ; 2.3 ; 5.2 ; 5.3 ; 6.1 ; 6.2 ; 6.3 ; \\
6.5\end{array}$ \\
\hline Victoria Villig & 26 & $6.1 ; 6.7$ & $\begin{array}{l}5.1 ; 5.3 ; \\
5.4 ; 5.5\end{array}$ & $\begin{array}{l}1.6 ; 5.2 ; 5.3 ; 6.1 ; 7.1 ; 7.2 ; 7.3 ; 9.1 ; \\
9.4 ; 9.6\end{array}$ \\
\hline MarttiHallikTV & 141 & 6.1 & $5.1 ; 5.3$ & $1.6 ; 2.1 ; 2.6 ; 6.2 ; 6.3 ; 6.6 ; 7.2 ; 9.5$ \\
\hline
\end{tabular}

